Original Research Article

\title{
Evaluation of anxiolytic activity of aqueous extract of Nerium oleander flowers in albino rats
}

\author{
Shashikala G. H., Shilpa B. N.*, Mansi J. Shah
}

Department of Pharmacology, JJM Medical College, Davangere, Karnataka, India

Received: 07 July 2018

Accepted: 30 July 2018

*Correspondence to:

Dr. Shilpa B. N.,

Email: shilpa.bennur22@ gmail.com

Copyright: (C) the author(s), publisher and licensee Medip Academy. This is an openaccess article distributed under the terms of the Creative Commons Attribution NonCommercial License, which permits unrestricted noncommercial use, distribution, and reproduction in any medium, provided the original work is properly cited.

\begin{abstract}
Background: Anxiety has become a very important area of research interest in psychopharmacology as it affects one-eighth of the population worldwide. Benzodiazepines are still the most commonly used drugs for anxiety despite a number of side effects.

There is a need for newer antianxiety drugs with increased safety and efficacy, hence this study was undertaken to evaluate the anxiolytic activity of Nerium oleander flowers.

Methods: Aqueous extract of Nerium oleander flowers (NA) was prepared using soxhalet apparatus. A total of 24 Albino rats aged 8-10 weeks of either sex weighing about 100-150g were obtained and divided into 4 groups of 6 rats each. Group I: Normal saline 10mL/kg. Group II: Diazepam 2mg/kg Group III: NA at a dose of $200 \mathrm{mg} / \mathrm{kg}$ Group IV: NA at a dose of $400 \mathrm{mg} / \mathrm{kg}$. The anxiolytic activity of Aqueous extract of NA was tested by elevated plus maze and digital actophotometer models. Data was analysed using one way ANOVA followed by Posthoc Tukey's test.

Results: In EPM model, the NA at $200,400 \mathrm{mg} / \mathrm{kg}$ doses showed that the number of entries and time spent in the open arms were increased significantly as compared to the control animals. $(\mathrm{p}<0.001)$. In Actophoptometer model, two different doses of NA (200 and 400mg/kg) showed a dose-dependent decrease in the locomotor activity, when compared to the control animals $(\mathrm{p}<0.001)$.

Conclusions: Both the doses of aqueous extract of Nerium oleander flowers (200mg and $400 \mathrm{mg} / \mathrm{kg}$ ) possess anxiolytic activity and could be used as a new approach to treat anxiety.
\end{abstract}

Keywords: Anxiolytic, Actophotometer, Elevated Plus Maze, Nerium oleander

\section{INTRODUCTION}

Anxiety disorders are the most common mental illnesses, affecting in excess of $10-15 \%$ of the population at some time in their lives. Anxiety disorders encompass a constellation of symptoms and include generalized anxiety disorder, obsessive-compulsive disorder, panic disorder, post-traumatic stress disorder, separation anxiety disorder, social phobia, specific phobias, and acute stress. ${ }^{1}$

Anxiety is an adaptive response which prepares person to face challenges in life. ${ }^{2}$
Major drug classes for the treatment of anxiety disorders are Benzodiazepines (BZDs), Selective serotonin-reuptake inhibitors (SSRIs), Tricyclic antidepressant and $\beta$ blockers. ${ }^{3}$

All these drug classes currently used are associated with side effects that vary in occurrence and severity. Like BZDs produce undesirable effects such as drowsiness, ataxia, sedation, muscle relaxation and insomnia. ${ }^{4}$ Hence there is a need to look for more efficacious anxiolytic agents with lesser side effects. Drugs obtained from natural sources are known to cause fewer side effects, but with same ability to cure disease. ${ }^{5}$ 
Nerium oleander, (Kaner in Hindi) is an evergreen shrub or small tree belonging to Apocynace NA family. It is so widely cultivated that NA precise region of origin has been identified though Southwest Asia has been suggested. Flowers are pink or white in color. ${ }^{6}$ Acute toxicity studies have shown lethal dose to be $2000 \mathrm{mg} / \mathrm{kg}^{7}$

Phytochemical study on aqueous extract of Nerium oleander flowers revealed the presence of various compounds such as alkaloids, saponins, flavones, triterpenoids, steroids, tannins and amino acids. ${ }^{8}$

The leaves and the flowers are cardiotonic, diaphoretic, diuretic, and emetic, expectorant. It has also been reported to have antibacterial and anti diabetic activities. ${ }^{9}$

Previous studies have shown dose dependent decrease in anxiety in rats when aqueous extract of Nerium oleander flowers was given at a dose of $100 \mathrm{mg} / \mathrm{kg}$ and $200 \mathrm{mg} / \mathrm{kg}$. Therefore, this study is undertaken to evaluate the anxiolytic property of aqueous extract of Nerium oleander flowers in rats in higher doses of $200 \mathrm{mg} / \mathrm{kg}$ and $400 \mathrm{mg} / \mathrm{kg}$.

Objectives of the study was to evaluate anxiolytic activity of aqueous extract of Nerium oleander flowers in albino rats in comparison to diazepam as standard.

\section{METHODS}

The study was initiated after seeking the necessary approval from the Institutional Ethics Committee, JJM Medical College in accordance with CPCSEA (Committee for the Purpose of Control and Supervision of Experiments on Animals, India).

\section{Plant}

The pink flowers of $N$. Oleander were collected from their natural habitat in Davangere city Karnataka, India and authentication was done at the Dept of botany, Davangere. Flowers were dried in shade, pulverized by a mechanical grinder and passed through mesh sieve to get the coarse powder.

\section{Preparation of extract}

The aqueous extract of flowers was prepared using the soxhlet apparatus in the Department of Pharmacology. The extract was dried, stored at room temperature and protected from direct sunlight.

\section{Selection of animals}

A total of 24 Albino rats aged 8-10 weeks of either sex weighing about 100-150g were obtained from the animal house of JJM Medical college, Davangere, India.

\section{Inclusion criteria}

- Healthy AlbiNA rats weighing 100-150gm.
- The rats previously unused for any experiments.

\section{Exclusion criteria}

Pregnant and diseased animals were NAt included in the study.

Duration of the study was 2 months.

\section{Drugs and chemicals}

Diazepam at a dose of $2 \mathrm{mg} / \mathrm{kg}$, Normal saline at a dose $10 \mathrm{ml} / \mathrm{kg}$ and Aqueous extract of Nerium oleander flowers (NA) at doses of $200 \mathrm{mg} / \mathrm{kg}$ and $400 \mathrm{mg} / \mathrm{kg}$ were used in this study. All drugs were given orally and administered one hour prior to testing.

The animals were divided into four groups of six rats each.

The drugs were administered as shown below:

- Group I: Control rats (normal saline $10 \mathrm{~mL} / \mathrm{kg}$ )

- Group II: Standard (diazepam $2 \mathrm{mg} / \mathrm{kg}$ )

- Group III: NA at a dose of $200 \mathrm{mg} / \mathrm{kg}$

- Group IV: NA at a dose of $400 \mathrm{mg} / \mathrm{kg}$.

\section{Laboratory models for evaluating anxiolytic activity}

Elevated plus maze (EPM) test

\section{Procedure}

The elevated plus-maze consists of two open arms, $43 \times 15 \mathrm{~cm}(\mathrm{~L} \times \mathrm{W})$, and two enclosed arms, $43 \times 15 \times 23 \mathrm{~cm}$ $(\mathrm{L} \times \mathrm{W} \times \mathrm{H})$, opened to the top, arranged in such way that the two open arms are faced opposite to each other. The maze is elevated to a height of $70 \mathrm{~cm} .{ }^{10}$

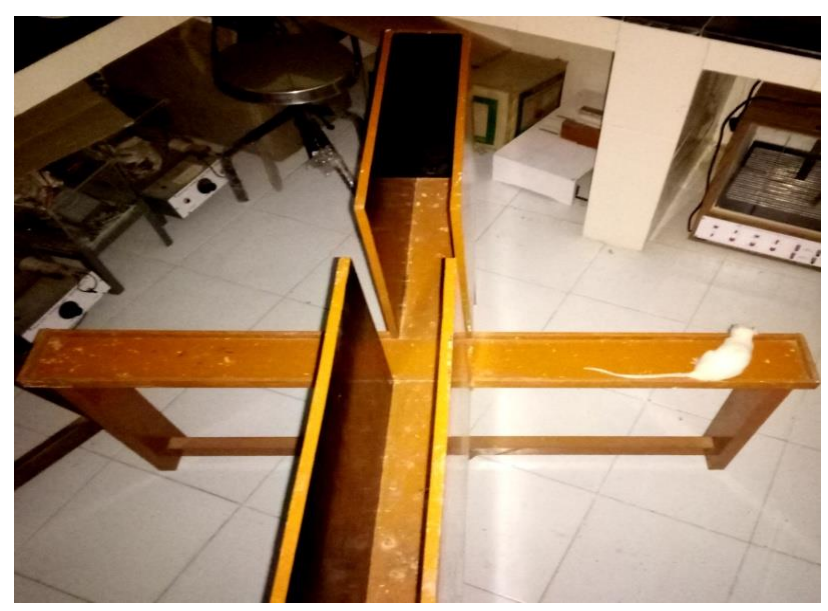

Figure 1: Elevated plus maze.

After one hour of oral administration of the test drug or the standard, the rat is placed at the centre of the maze, facing towards one of the enclosed arms. After 5min of observation the following parameters are noted: 
- The number of entries into open arm and closed arms

- Time spent in the open and enclosed arms (Figure 1).

\section{Digital Actophotometer}

\section{Procedure}

A continuous beam of light from six lights will be made to fall on corresponding photoelectric cells, the photoelectric cells will get activated when an animal crosses the beam of light and thereby cuts off (crossing) the rays of light falling on it. These crossings are counted automatically for a period of $10 \mathrm{~min}$ by the machine. The number of cuts off was taken as a parameter of the locomotor activity of the rats. ${ }^{5}$

Rats are placed in the digital actophotometer $1 \mathrm{hr}$ after drug administration and number of crossings are counted for a period of $10 \mathrm{~min}$ (Figure 2).

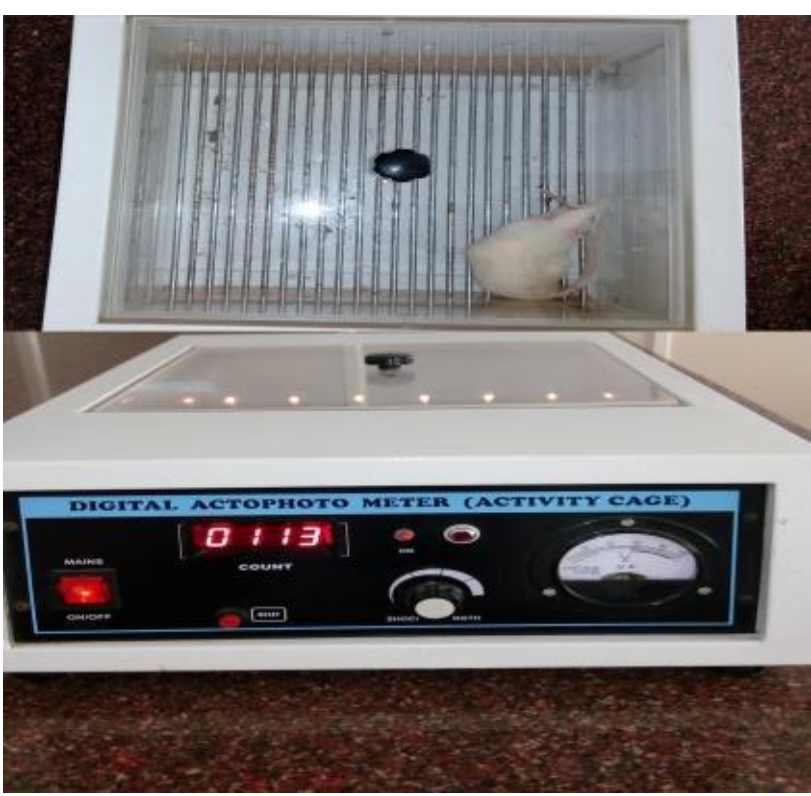

Figure 2: Actophotometer model.

\section{Statistical analysis}

Statistical analysis was carried out with SPSS version 20 for windows. Mean and standard deviation were calculated for continuous variables.

Comparison of four groups was done with One Way Analysis of Variance (ANOVA). Multiple comparisons done with Tukey's Post Hoc.

\section{RESULTS}

In EPM model, the anxiolytic effect is measured by the number of entries and time spent in open arms. The NA at $200,400 \mathrm{mg} / \mathrm{kg}$ doses showed that, the mean number of entries in open arm is 7.17 \pm 2.64 and $6.33 \pm 1.21$ respectively which is significantly higher when compared with control i.e. $2.5 \pm 0.55$. The NA at $200,400 \mathrm{mg} / \mathrm{kg}$ doses also increased the time spent in open arm, 111.83 \pm 8.54 secs and $113.67 \pm 35.17$ secs respectively which is significantly higher compared to control group i.e. 64.83 \pm 17.95 secs (Table 1 and Figure 3 and 4).

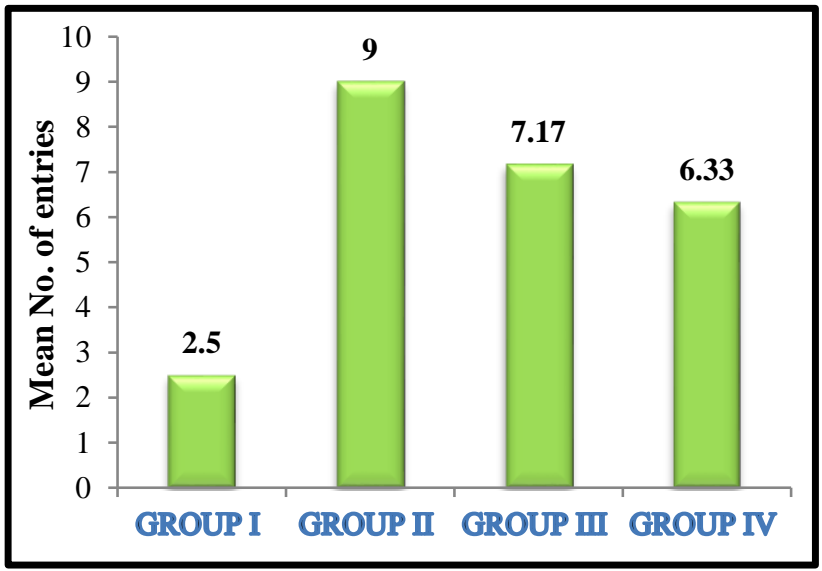

Figure 3: Elevated plus maze: no. of entries in open arm.

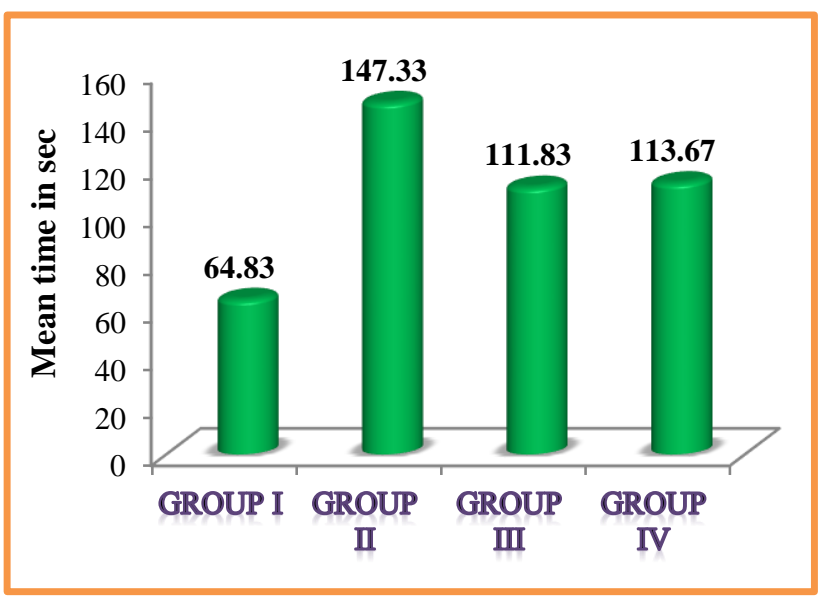

Figure 4: Elevated plus maze: time spent in open arm.

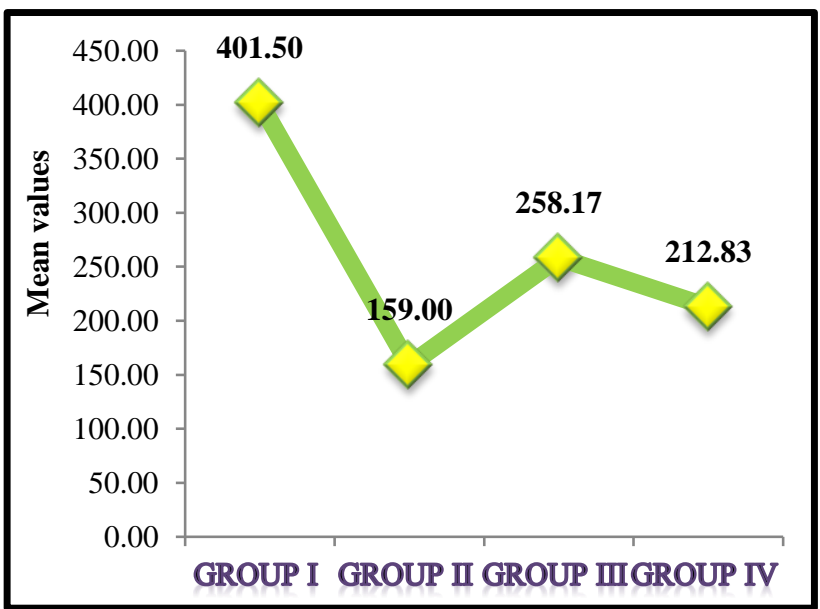

Figure 5: No. of crossings in Actophotometer. 
Table 1: Effects of NS (Group I), Diazepam (Group II), NA: 200mg/kg (Group III) and 400mg/kg (Group IV) IN EPM and Actophotometer.

\begin{tabular}{|lllllll|}
\hline & & \multicolumn{2}{l}{ Elevated plus maze } & \multicolumn{2}{c|}{ Actophotometer } \\
\hline Groups & & Number of entries & \multicolumn{2}{l}{ Time spent in (Secs) } & Locomotor activity \\
\hline Group I & Control (NS) & Closed & Open & Closed & Open & \\
\hline Group II & Standard (DZ) & $5.33 \pm 1.97$ & $2.5 \pm 0.55$ & $199.67 \pm 45.70$ & $64.83 \pm 17.95$ & $401.50 \pm 55.67$ \\
\hline Group III & NA 200mg/kg & $3.67 \pm 1.86$ & $7.17 \pm 2.61$ & $120 \pm 41.19$ & $147.33 \pm 16.65$ & $159.00 \pm 33.65$ \\
\hline Group IV & NA 400 mg/kg & $2.67 \pm 1.03$ & $6.33 \pm 1.21$ & $143 \pm 20.54$ & $111.83 \pm 8.54$ & $258.17 \pm 19.35$ \\
\hline
\end{tabular}

Results are expressed as Mean value \pm SD (standard deviation). $n=6$ (NA. of animals in each group), NS- Normal Saline, DZ- diazepam, NA - Aqueous EXTRACT of Nerium oleander flowers

Table 2: Comparison of results between the groups (control, standard and test groups) using unpaired $t$ test and significance.

\begin{tabular}{|c|c|c|c|c|c|}
\hline \multirow{3}{*}{ Group comparison } & \multicolumn{5}{|c|}{ Unpaired $t$ test and significance } \\
\hline & \multicolumn{2}{|c|}{ No. of entries in } & \multicolumn{2}{|c|}{ Time spent in } & \multirow[t]{2}{*}{ Locomotor activity } \\
\hline & Open arm & Closed arm & Open arm & Closed arm & \\
\hline Group I vs II & $\mathrm{P}<0.0001$ & $\mathrm{P}<0.03$ & $\mathrm{P}<0.0001$ & $\mathrm{P}<0.008$ & $\mathrm{P}<0.0001$ \\
\hline Group I vs III & $\mathrm{P}<0.003$ & $\mathrm{P}<0.003$ & $\mathrm{P}<0.007$ & $\mathrm{P}<0.007$ & $\mathrm{P}<0.0001$ \\
\hline Group I vs IV & $\mathrm{P}<0.01$ & $\mathrm{P}<0.0001$ & $\mathrm{P}<0.002$ & $\mathrm{P}<0.02$ & $\mathrm{P}<0.0001$ \\
\hline Group II vs III & $P=0.395$ & 0.643 & $\mathrm{P}<0.04$ & 0.717 & $\mathrm{P}<0.001$ \\
\hline Group II vs IV & $\mathrm{P}<0.04$ & $\mathrm{P}<0.005$ & $\mathrm{P}<0.05$ & 0.965 & $\mathrm{P}<0.002$ \\
\hline Group III vs IV & $P=0.884$ & 0.811 & 0.999 & 0.934 & $\mathrm{P}<0.002$ \\
\hline
\end{tabular}

In Actophoptometer model, spontaneous locomotor activity is measured and compared between the groups. Standard drug Diazepam significantly reduced the number of crossings of light beams which is taken as locomotor activity when compared to control $(401.50 \pm 50)(\mathrm{p}<0.001)$. Animals treated with NA $400 \mathrm{mg} / \mathrm{kg}$ showed greater decrease in locomotor activity $(212.83 \pm 37.04)$ than animals treated with NA $200 \mathrm{mg} / \mathrm{kg}(258.17 \pm 19.35)$ and therefore showed a statistically significant dose-dependent anxiolytic effect of NA $(\mathrm{p}<0.002)$ (Table 2$)$. The reduction in locomotor activity with $200 \mathrm{mg} / \mathrm{kg}$ and $400 \mathrm{mg} / \mathrm{kg}$ is significantly when compared to standard group

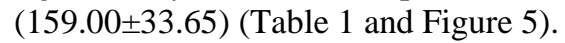

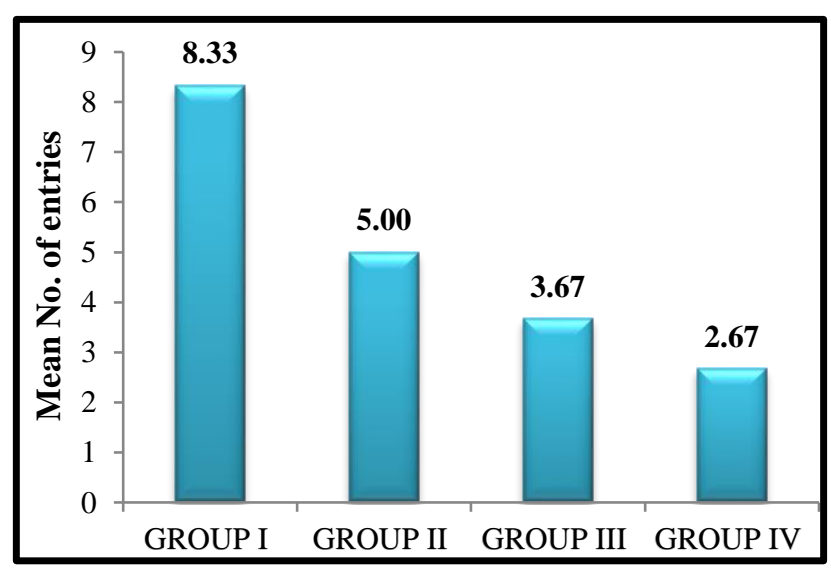

Figure 6: Elevated plus maze: no. of entries in closed arm.
Effects of NS (Group I), Diazepam (Group II), NA: $200 \mathrm{mg} / \mathrm{kg}$ (Group III) and NA: 400mg/kg (Group IV); on Number of entries in EPM $(\mathrm{P}<0.001)$.

Number of closed arm entries and time spent in the closed arms were decreased significantly as compared to the control animals ( $p<0.001)$ (Figure 6 and 7). Standard drug, Diazepam showed significant increase in open arm activity by increase in time spent and number of entries into open arms when compared to control $(\mathrm{P}<0.05)$. It was found that there is no significant difference in the number of open arm entries and time spent in open arm between the doses of $200 \mathrm{mg} / \mathrm{kg}$ and $400 \mathrm{mg} / \mathrm{kg}(\mathrm{p}=0.8)$ which indicates that the NA has no dose dependent anxiolytic activity (Table 2).

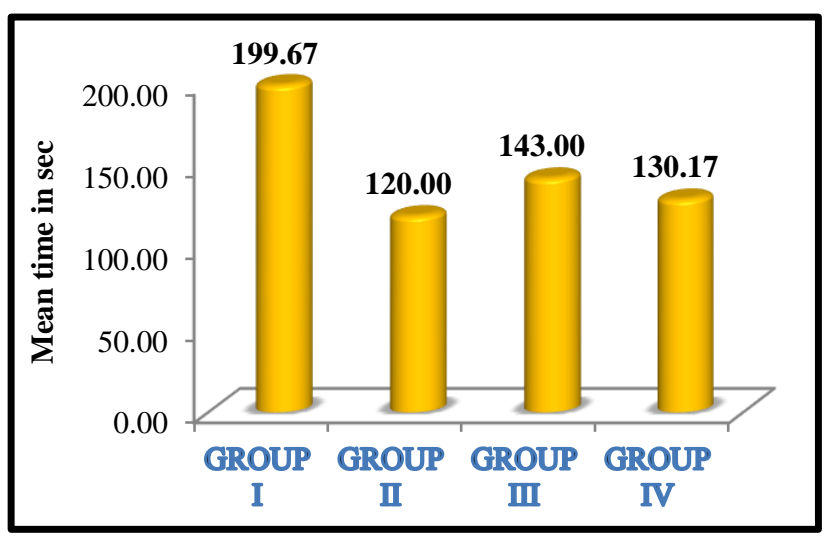

Figure 7: Elevated plus maze: time spent in closed arm. 
Effects of NS (Group I), Diazepam (Group II), NA: $200 \mathrm{mg} / \mathrm{kg}$ (Group III) and 400mg/kg (Group IV); on number of entries in closed arm $(\mathrm{P}<0.001)$.

Effects of NS (Group I), Diazepam (Group II), NA: $200 \mathrm{mg} / \mathrm{kg}$ (Group III) and 400mg/kg (Group IV); on time spent in open arm $(\mathrm{P}<0.001)$.

Effects of NS (Group I), Diazepam (Group II), NA: $200 \mathrm{mg} / \mathrm{kg}$ (Group III) and 400mg/kg (Group IV); on time spent in closed arm $(\mathrm{P}<0.001)$.

Effects of NS (Group I), Diazepam (Group II), NA: $200 \mathrm{mg} / \mathrm{kg}$ (Group III) and 400mg/kg (Group IV); on locomotor activity in actophotometer $(\mathrm{P}<0.001)$.

\section{DISCUSSION}

In the present study, we have used two standard models, EPM and Actophotometer to evaluate the anxiolytic effect of NA.

Elevated plus maze is a model used for identification of 'anxiogenic and anxiolytic' drug effects in rodents (REF). In EPM, rodents normally prefer to spend more time in closed arms as they be afraid for open spaces which reflects their anxiety behaviour (REF). Hence reduction in anxiety would be expected to increase the time spent in open arms.

In this study, the NA at $200,400 \mathrm{mg} / \mathrm{kg}$ doses showed that the number of open arm entries and time spent in the open arms were increased significantly when compared to control group (Table 1 and Figure 1 and 3). There was no dose dependent anxiolytic activity with higher dose of NA (400mg/kg), hence higher doses may not be necessary for anxiolytic activity. The effect of NA is almost comparable with the standard drug diazepam in this model.

Observations from our study is consistent with the study conducted by Singhal KG, Gupta GD et al. with doses of $100 \mathrm{mg} / \mathrm{kg}$ and $200 \mathrm{mg} / \mathrm{kg}$ of the ethyl alcohol extract of Nerium oleander flowers. ${ }^{11}$

Actophotometer is a model for locomotor activity. Decrease in locomotor activity implies a depressive effect on CNS. ${ }^{12}$

The NA showed dose dependent decrease in locomotor activity compared to control animals. These observations are similar to the results of the study conducted by $\mathrm{M}$. Rabbani et al. ${ }^{13}$

Phytochemical tests of NA revealed the presence of alkaloids, tannins, cardiac glycosides, terpenoids, reducing sugars, anthraquinones, flavonoids, saponins. ${ }^{14}$ Various studies have shown that the possible mechanism of anxiolytic action of NA could be due to the binding of flavonoids to the $\mathrm{GABA}_{\mathrm{A}}$ - BZD receptor complex leading to agonistic action. ${ }^{15}$
It is well known that the standard anxiolytic drug diazepam also acts by binding to BZD receptors and induce their effect on GABNArgic system in the brain. ${ }^{16}$ In this study, NA containing flavanoids could be acting by the similar mechanism. Further studies are required to know the exact mechanism responsible for antianxiety activity.

\section{CONCLUSION}

From the above observations we can conclude that aqueous extract of Nerium oleander flowers showed anxiolytic activity at both the doses $(200$ and $400 \mathrm{mg} / \mathrm{kg})$. NA can be a safe and effective approach/alternative for the treatment of number of anxiety disorders. More extensive study is necessary to determine the exact mechanism of action of the extract and its active ingredients.

\section{ACKNOWLEDGEMENTS}

Authors would like to thank the Post graduate students and Professors of Department of Pharmacology. Authors would also like to extend my thanks to the animal house and Biostatistician of JJMMC, Davangere, India.

Funding: No funding sources

Conflict of interest: None declared

Ethical approval: The study was approved by the Institutional Ethics Committee of JJM Medical College (Committee for the Purpose of Control and Supervision of Experiments on Animals, India Ref No. JJMMC/IAEC/O22016)

\section{REFERENCES}

1. Brunton LL, Lazo JS, Parker KL. Drug therapy of depression and anxiety disorders: Goodman and Gilman's The Pharmacological Basis of Therapeutics. $11^{\text {th }}$ Ed. New York: McGraw-Hill; 2006:430,680.

2. HL Sharma, KK Sharma. Anxiolytics and HypNAtics: Principles of Pharmacology. $2^{\text {nd }}$ Ed. Hyderabad: Paras medical publisher; 2007:442.

3. KuNAvac JL, Stahl SM. Future directions in anxiolytic pharmacotherapy. Psychiatry. Clin. NArth Am. 1995; 18:895-909.

4. Palva ES, LinNAila M, Saario I, Mattila M. Acute and subacute effects of diazepam on psychomotor skills; interactions with alcohol. Acta pharmacol. Toxicol. 1979;45:257-64.

5. Halemani D. Evaluation of anti-anxiety activity of methanol extract of aegle maemelos (Bael fruit tree) leaves in rats. IOSR-JDMS. Sept 2015;14(9):01-5.

6. Lokesh R, Barnalas L, Madhuri P, Saurav K, Sundar K. Larvicidal activity of Trigonella, foenum and Nerium oleander Linn. Curr Res J Biol Sci. 2010;2:154-60.

7. OECD/OCDE guidelines 425 for testing of chemicals, acute oral toxicity up-and-down- procedure (UDP) along with the conventional LD50 test and the fixed dose procedure (FDP), OECD test guidelines 420 and 
423. Adopted $3^{\text {rd }}$ October 2008. Available at: http://www.oecd.org.

8. Satti AA, Edriss NA. Phytochemical analyses of three sudanese plants for their constituents of bioactive compounds. Int J Sci Nat. 2013;4:169-73.

9. Al-Nagger TB, Gómez-Serranillos MP, Carretero MP, Villar AM. Neuropharmacological activity of $\mathrm{N}$. sativa L. J Eth NA pharmacol. 2003;88:63-8.

10. Pellow S, File SE. Anxiolytic and axiogenic drug effects on exploratory activity in an elevated plusmaze a NAvel test of anxiety in the rat. Pharmacol Biochem Behav. 1986;24:525-9.

11. Singhal KG, Gupta GD. Some central nervous system activities of Nerium oleander Linn (Kaner) flower extract. Trop J Pharm Res. 2011;10:455.

12. Leewanich $\mathrm{P}$, Tohda $\mathrm{M}$, Matsumoto KE, Subhadhirsakul S, Takayama $H$, Watanbe $H$. Behavioural studies on alkaloids extracted from leaves of Hunteria zeylanica, Biol Pharm Bull. 1996;19:3949.

13. Rabbani M, Sajjadi SE, VN Azi1 A. Evaluation of anxiolytic and sedative effect of essential oil and hydroalcoholic extract of Ocimum basilicum L. and chemical composition of its essential oil. Research in Pharmaceutical Sciences. 2015;10(6):535-43.

14. Zia A, Siddiqui BS, Begum S, Siddiqui S, Suria A. Studies on the constituents of the leaves of Nerium oleander on behavior pattern in mice. $\mathbf{J}$ EthNApharmacol. 1995;49(1):33-9.

15. Adome RO, Gachihi JW, Onegi J, Tamel J, Apio SO. The cardio tonic effect of the crude ethaNAlic extract of Nerium oleander in the isolated guinea pig hearts. Afr Health Sci. 2003;3(2):77-82.

16. Lumdberg D, Breese GR, Nicoll RA, Eccles JC, Oshima T, Rubia F. prolongation of hippocampal inhibitor postsynaptic potential by barbiturates. Nature. 1975;258:625-7.

Cite this article as: Shashikala $\mathrm{GH}$, Shilpa BN, Shah MJ. Evaluation of anxiolytic activity of aqueous extract of Nerium oleander flowers in albino rats. Int J Basic Clin Pharmacol 2018;7:1797-802. 